\title{
A doença de Chagas no contexto da prática esportiva
}

\author{
Recomendações*
}

- Todas as pessoas que pretendem executar atividades esportivas ou já estão desenvolvendoas devem ser submetidas à avaliação clínica, no decurso da qual a doença de Chagas precisa ser cogitada, cabendo atenção especial para o acometimento cardíaco, inclusive com a realização de exame radiológico, evidentemente havendo obrigatoriedade de contar com eletrocardiograma.

- Conhecimento de ter havido possibilidade de contrair a infecção parasitária que motiva a doença de Chagas através de triatomíneo ("barbeiro") facilita a suspeita e é informação imprescindível.

- A confirmação do diagnóstico da doença em fase crônica, que é a cogitável na situação avaliada, terá lugar por meio de provas sorológicas. É obrigatório solicitar pelo menos duas, entre as disponíveis, exemplificadas por ELISA, hemaglutinação indireta e imunofluorescência indireta. É imperioso que sejam realizadas em Laboratório de Patologia Clínica confiável.

- A detecção de anormalidades clínicas, radiológicas ou eletrocardiográficas concernentes aos coração constitui empecilho para a realização de atividades físicas de caráter esportivo. Tal orientação tem nexo com riscos já devidamente comprovados.

- Quanto à forma crônica denominada indeterminada, demarcada por exames clínico, radiológico e eletrocardiográfico normais, tendo sido criteriosamente analisados, não deve haver restrição de atividades esportivas, de acordo com os conhecimentos científicos atualmente disponíveis.

- Inexistem informações capazes de justificar atitudes quando estão presentes megas sem distúrbios cardíacos documentados.

- Não é possível atualmente estipular estratificação de riscos, cabível a propósito de algumas outras enfermidades, como a coronariopatia, em virtude da falta de respaldo categórico.

- Igualmente, não é viavel presentemente pretender estabelecer graus de atividades permitidas, pois não há disponibilidade de elementos capazes de orientar a aceitação dessa cogitação. O desconhecimento cabal da história natural da doença de Chagas impede que se convencione quais são as permissividades toleráveis.

- Os indivíduos avaliados, clubes e demais entidades nas quais são praticadas atividades esportivas têm obrigação de acatar e fazer cumprir estas recomendações, em virtude da intenção preventiva nelas contida.

Orientações específicas, sempre que necessárias, serão gentilmente fornecidas pelo Setor de Cardiologia do Esporte, do Instituto "Dante Pazzanese" de Cardiologia, e pela Unidade de Cardiopatias Gerais, do Instituto do Coração.

\footnotetext{
* Elaboradas por Charles Mady, Instituto do Coração do Hospital das Clínicas da Faculdade de Medicina da Universidade de São Paulo, Giuseppe Sebastiano Dioguardi e Nabil Ghorayeb, Instituto "Dante Pazzanese" de Cardiologia da Secretaria de Estado da Saúde de São Paulo, e Vicente Amato Neto (Coordenador), Instituto de Medicina Tropical de São Paulo da Faculdade de Medicina da Universidade de São Paulo.
} 